\title{
Importance of Orphan Drugs Needs More Attention in Future
}

\author{
Bind $\mathrm{V}^{1}$ and Kumar $\mathrm{A}^{2 *}$ \\ ${ }^{1}$ Dept of Zoology, KN Govt PG College, India \\ ${ }^{2}$ Toxicology Division, CIB \& RC, India
}

*Corresponding author: Dr. Akhilesh Kumar, Ex -Consultant (Medical Toxicology),

\section{Short Communication}

Volume 4 Issue 4

Received Date: September 16, 2019

Published Date: October 14, 2019

DOI: $10.23880 /$ act- 16000167

Toxicology Division, CIB \& RC, Faridabad, Haryana, India-121001, Tel: +91- 9565490599; Email: akhilcibrc@gmail.com

\section{Abstract}

The orphan drugs or products were not very economically beneficial for pharmaceutical industry due to less number of patients. However, these rare diseases have no any satisfactory treatment in the markets. Currently after so much development many patients are suffering. The government of various countries aware more nowadays, taking more steps against such cases and also taking attention for the development of such products for human welfare. According to UNICEF (US) the number of Orphans children's in countries around the world about 2.7 million. The Eastern Europe is placed at the highest rate in the world for drops. In Asia, China on top but when we saw in INDIA, the government reported approximately there are 20 million orphans and abandoned children. In conclusion, there is more attention needs for such rare cases.

Keywords: Rare Disease; Orphan Drugs; Patients; Disable; Suffering

\section{Introduction}

The Orphan drugs are those drugs which are used to treat rare diseases. According to FDA it's affecting less than one in two lakh peoples in US. Orphan Products Development mission has provides incentives for sponsors which involve in the developing products (drugs, biologics, devices, or medical foods) for rare diseases. Under this mission more than 600 drugs and biologic products as Orphan Products in the markets since 1983. Now days, the clinical trial grants program has provided support for conducting clinical studies for the safety and efficacy of drugs or medical devices by the deep analysis of the family history background of the particular rare diseases [1].

From 1983 to mid 2019, total 5103 products are designated and in which 820 products are designated and approved, however 719 are designated and withdraw (FDA). The first products two products Diaziquone (1983) and Alpha-1-antitrypsin (1984) are designated/ withdrawn by the FDA. The product Diaziquone designated for the treatment of primary brain malignancies and the Alpha-1-antitrypsin used as a supplementation therapy for alpha-1-antitrypsin deficiency in the ZZ phenotype population [2]. The four products were Designated/Approved/Withdrawn from 1984 to 1988. These are Iobenguane Sulfate I 131 used as a diagnostic adjunct in the pheochromocytoma suffering patients, Ganciclovir sodium used for the treatment of cytomegalovirus retinitis in immune compromised patients with AIDS, tranexamic acid was use in patients which are undergoing some surgical procedures, e.g. dental extractions and have congenital coagulopathies and fourth was Gallium nitrate injection which was used for the treatment of hypercalcemia of malignancy(FDA). 


\section{Advances in Clinical Toxicology}

The research work with the development of Orphan drugs after the 2003 extremely boost in the designation as more than 100 and riches to more than 200 products in the year 2010 [3]. However, it crosses more than 300 products within five year and maximum designated products was in 2017 nearly 500 products. The orphan drugs development process enhancing continues but has several problems. First, it's for rare diseases which are genetic or having negligible symptoms and most of the cases don't recognize due to suffering patient die at very early age of life. Scientist now days aware more about the rare diseases and they are taken responsibility for confiscate the burden from the societies. Now the government aware and provided the funds for research and development program for the products. However, the problems behind the R\&D of Orphan products due to less number of patient samples, high cost of treatments. According to a new study report, the valued of global orphan drugs market was about US\$ 125000 million in 2017 and this will cross the its double at the end of year 2025 [4].

In the case of disable birth child's or when the families diagnose her baby is abnormal than they feel very embarrassing for society. They curse him and such families cannot support the affected child because in most of the time the high costs of medical treatment or in some time the defects or abnormality cannot be cure or some time they diagnose later in the life. The families with such babies left her child alone in the open filed or public or private places. In the United States foster care effort good for orphan and government also enforce many rules for take care to him. In the favor of child European Union has also provided millions of dollars.

\section{Acknowledgement}

Mrs. Vimala Bind contributing in the preparation of manuscript.

\section{Conflict of Interest}

The authors declare that there is no Conflict of interests.

\section{References}

1. Auvin (2018) The Low-income and middle-income countries (LMICs), have 360-480 million patients with rare diseases, they are in need of orphan drugs/ products.

2. Gammie T, Lu CY, Babar ZU-D (2015) Access to orphan drugs: a comprehensive review of legislations, regulations and policies in 35 countries. PLoS One 10(10): e0140002.

3. Auvin S, Irwin J, Abi-Aad P, Battersby A (2018) The problem of rarity: estimation of prevalence in rare disease. Value Health 21(5): 501-507.

4. Mutler A, Wong G, Crary D (2017) Global effort to get kids out of orphanages gains momentum. AP NEWS. 